\title{
Cortical Activation during Spoken-Word Segmentation in Nonreading-Impaired and Dyslexic Adults
}

\author{
Päivi Helenius, ${ }^{1}$ Riitta Salmelin, ${ }^{1}$ Elisabet Service, ${ }^{2}$ John F. Connolly, ${ }^{3}$ Seija Leinonen, ${ }^{4}$ and Heikki Lyytinen ${ }^{4}$ \\ ${ }_{1}^{1 B}$ Brain Research Unit, Low Temperature Laboratory, Helsinki University of Technology, FIN-02015 HUT, Espoo, Finland, \\ 2Department of Psychology, University of Helsinki, FIN-00014 Helsinki, Finland, 32Department of Psychology, Life Sciences \\ Center, Dalhousie University, Halifax, Nova Scotia, Canada, B3H 4J1, and ${ }^{4}$ Department of Psychology, University of \\ Jyväskylä, FIN-40351 Jyväskylä, Finland
}

\begin{abstract}
We used magnetoencephalography to elucidate the cortical activation associated with the segmentation of spoken words in nonreading-impaired and dyslexic adults. The subjects listened to binaurally presented sentences where the sentence-ending words were either semantically appropriate or inappropriate to the preceding sentence context. Half of the inappropriate final words shared two or three initial phonemes with the highly expected semantically appropriate words. Two temporally and functionally distinct response patterns were detected in the superior temporal lobe. The first response peaked at $\sim 100$ msec in the supratemporal plane and showed no sensitivity to the semantic appropriateness of the final word. This presemantic N100m response was abnormally strong in the left hemisphere of dyslexic individuals. After the N100m response, the semantically inappropriate sentence-ending words evoked stronger activation than the expected endings in the superior
\end{abstract}

temporal cortex in the vicinity of the auditory cortex. This $\mathrm{N} 400 \mathrm{~m}$ response was delayed for words starting with the same two or three first few phonemes as the expected words but only until the first evidence of acoustic-phonetic dissimilarity emerged. This subtle delay supports the notion of initial lexical access being based on phonemes or acoustic features. In dyslexic participants, this qualitative aspect of word processing appeared to be normal. However, for all words alike, the ascending slope of the semantic activation in the left hemisphere was delayed by $\sim 50 \mathrm{msec}$ as compared with control subjects. The delay in the auditory $\mathrm{N} 400 \mathrm{~m}$ response in dyslexic subjects is likely to result from presemantic-phonological deficits possibly reflected in the abnormal $\mathrm{N} 100 \mathrm{~m}$ response.

Key words: speech processing; lexical access; N400m; temporal cortex; reading impairment; magnetoencephalography
Children with developmental dyslexia have difficulties in reading acquisition and reaching a level of reading fluency that could be expected on the basis of their age or intelligence. Beginning readers must learn that spoken words are composed of speech sounds, phonemes, which can be represented by corresponding letters, graphemes, in written language. Phonological skills at preschool age predict later success in reading (Lundberg et al., 1980; Bradley and Bryant, 1983). Accordingly, children who have impaired phonological skills are likely to experience difficulties in reading acquisition (Bradley and Bryant, 1983; Scarborough, 1990).

Behavioral studies have shown that the discrimination of syllables / ba/ and /da/ is impaired in dyslexic individuals. In addition, reading-impaired children are less consistent than their nonreading-impaired peers in labeling syllables on the synthetic continuum from / ba/ to /da/ (Reed, 1989). Thus, it seems that in dyslexic children the phonological categories are broader and less sharply defined for these speech sounds that begin with rapid

Received Oct. 25, 2001; revised Jan. 17, 2002; accepted Jan. 18, 2002.

This work was supported by the Academy of Finland Grants 32731, 1365981, and 39253, Human Frontier Science Program Grant RG82/1997-B, Finnish Cultural Foundation, and Wihuri Foundation. We thank K. Eklund and K. Müller for assistance in recruiting the subjects and gathering the behavioral data, R. Service for reading the sentences to the tape, $\mathrm{P}$. Antsalo for valuable help in stimulus recordings, A. Tarkiainen for providing the program for the areal mean signal calculations, and M. Seppä for providing the average brain.

Correspondence should be addressed to Dr. Päivi Helenius, Brain Research Unit, Low Temperature Laboratory, Helsinki University of Technology, P.O. Box 2200, FIN-02015 HUT, Espoo, Finland. E-mail: paivi@neuro.hut.fi.

Copyright (C) 2002 Society for Neuroscience $0270-6474 / 02 / 222936-09 \$ 15.00 / 0$ formant transitions. Furthermore, the mismatch response evoked by rarely presented speech sounds /ba/ in a sequence of more often presented speech sounds/da/ has been reported to be abnormally small in dyslexic children 300-600 msec after speech sound onset (Schülte-Körne et al., 1998). Recent behavioral studies have also suggested that the perception of vowels can be impaired in dyslexia (Adlard and Hazan, 1998).

The analysis of spoken words is composed of various subprocesses like acoustic, phonetic, phonological, semantic, and syntactic analysis, the temporal involvement of which can only be followed by time-sensitive methods like electroencephalography (EEG) and magnetoencephalography (MEG). However, the correspondence between auditory event-related potentials (ERPs), peaking in distinct time windows and the different operations involved in speech processing still has not been clearly determined. ERP studies have used the N400 paradigm both in the visual and auditory domains to tap semantically sensitive activation (for review, see Osterhout and Holcomb, 1995; Kutas and Federmeier, 2000). In their seminal study, Kutas and Hillyard (1980) used sentences with either expected or semantically inappropriate final words. The inappropriate endings evoked an N400 response, a negative deflection peaking $\sim 400 \mathrm{msec}$. Using conventional scalp-recorded ERPs, the localization and accurate description of the time behavior of the N400 has been complicated.

We recently used MEG to clarify the spatial and temporal pattern of semantic activation during reading (Helenius et al., 1998). Semantically inappropriate sentence-ending words evoked stronger activation than expected endings most consistently in the 
Table 1. The behavioral profiles of control and dyslexic subjects

\begin{tabular}{|c|c|c|c|c|c|c|}
\hline & \multicolumn{2}{|c|}{ Control subjects } & \multicolumn{2}{|c|}{ Dyslexic subjects } & \multirow[b]{2}{*}{$t$ value (DF) } & \multirow[b]{2}{*}{$p$} \\
\hline & Mean (SD) & Range & Mean (SD) & Range & & \\
\hline Age (years) & $34.8(4.1)$ & $28-40$ & $35.6(6.8)$ & $28-50$ & $0.3(17)$ & ns \\
\hline Raven IQ & $116(14)$ & $98-132$ & $109(20)^{a}$ & $80-132^{a}$ & $-1.0(16)$ & ns \\
\hline Oral reading ${ }^{b}$ & $374(56)^{a}$ & $315-500^{a}$ & $645(88)$ & $540-850$ & $7.5(16)$ & $* * *$ \\
\hline Oral reading errors $(\%)$ & $0.5(0.4)^{a}$ & $0-1.2^{a}$ & $4.6(2.4)$ & $1.7-9.2$ & $4.7(16)$ & $* * *$ \\
\hline Spelling errors $(\%)$ & $14.4(9.8)^{a}$ & $0-25^{a}$ & $42.0(27.6)^{a}$ & $10-95^{a}$ & $2.7(16)$ & $*$ \\
\hline
\end{tabular}

SD, Standard deviation; DF, degrees of freedom; *** $p<0.001 ;{ }^{*} p<0.05$; ns, nonsignificant.

${ }^{a}$ Value missing in one individual.

${ }^{b}$ The speed of reading aloud a narrative (milliseconds per word).

left superior temporal cortex. In dyslexic individuals the onset of semantic activation was delayed (Helenius et al., 1999a). Furthermore, unlike in control subjects, in dyslexic individuals the $\mathrm{N} 400 \mathrm{~m}$ response was weaker to inappropriate words that began with the expected letters. This suggests that visual word recognition may occur in atypically small sublexical units in dyslexic readers.

In the current study we elucidated the cortical location, timing, and rules in auditory word recognition. We studied both nonreading-impaired and dyslexic adults to determine whether phonological deficits associated with reading problems manifest as differences in the cortical responses elicited by naturally spoken words.

\section{MATERIALS AND METHODS}

Subjects. A total of nine nonreading-impaired adults (five females and four males) and 10 adults with a history of developmental dyslexia (five females and five males) took part in the study. The dyslexic adults were recruited from the population of the Jyväskylä Longitudinal Study of Dyslexia (JLD) (Lyytinen, 1997). The inclusion criteria used in the JLD study for selecting dyslexic individuals are: self-reported childhood and present reading and/or writing difficulties, below-normal reading and/or spelling test performance, intelligence quotient $>80$ (Raven et al., 1992), and dyslexia among close relatives (for details, see Leinonen et al., 2001). Individuals with a medical history of sensory or neurological abnormalities are excluded. The nonreading-impaired individuals were either spouses of the dyslexic individuals or age-matched control subjects that had no history of reading difficulties and a present reading performance within norms.

The dyslexic individuals had been tested with the standard behavioral test battery used in the JLD study within a few years of the MEG measurement (Leinonen et al., 2001). Control subjects were also tested for IQ and reading and spelling performance before the MEG recording. The subject groups did not differ in nonverbal IQ (Raven et al., 1992), but compared with control subjects the dyslexic participants were significantly slower and more error prone in reading aloud text passages, and made more errors in spelling aloud words and pseudowords presented aurally (Table 1 ). Compared with a normative sample of 100 nonreadingimpaired adults (Leinonen et al., 2001), the dyslexic adults of the present study were also impaired in phonological awareness tasks. Dyslexic subject were successful in deleting a phoneme from a word on average 7.2 times $( \pm$ SD 4.4$)$ of 16 trials, whereas the mean of the normative sample was $13.0( \pm 3.5)\left(t_{(108)}=3.9 ; p<0.0005\right)$. In a syllable reversal task the dyslexic subject succeeded on average 4.0 times $( \pm 3.3)$ of 20 trials, whereas the mean of the normative sample was $15.3( \pm 4.5)$ $\left(t_{(106)}=8.5 ; p<0.0001\right)$. The oral reading speed of every dyslexic individual was at least 2 SDs below the mean of the normative sample and in at least one of the phonological awareness tasks $70 \%$ of the dyslexic individuals scored $<2$ SDs of the mean of the normative sample (Leinonen et al., 2001).

Materials. We used Finnish sentences with four types of final words, graded with respect to their appropriateness to the preceding sentence context (Helenius et al., 1998, 1999a). Some of the sentences were modified from the English versions used by Connolly and Phillips (1994) and Connolly et al. (1995). In the expected condition, the last word of a sentence was semantically appropriate and highly probable to that sentence context (e.g., "The piano was out of tune"). Alternatively, expected ending could be replaced by an improbable final word, i.e., a word that was semantically appropriate but of low probability with respect to the preceding sentence context (e.g., "The crying baby woke up her sitter"). In the phonological condition, the expected word was replaced by a semantically inappropriate final word beginning with the same two or three phonemes as the most probable word (e.g., "The gambler had a streak of bad luggage"). In the anomalous condition the final word was both semantically and phonologically totally inappropriate to the preceding sentence context (e.g., "The traffic lights changed from red to sun$n y$ "). The total number of sentences was 400 (100 sentences per condition). Presentation order of sentences was randomized.

Sentences were recorded using a male voice on a DAT tape in an anechoic chamber (Acoustics Laboratory, Helsinki University of Technology). The sentences were presented for reading on a computer screen one word at a time at a rate of approximately one word per second. Thus, across-word coarticulatory or prosodic cues were minimal. The sentences were edited so that a constant $750 \mathrm{msec}$ silent gap always preceded the last word of the sentence. The length of the final word was on average 490 msec (SD $80 \mathrm{msec})$. Each new sentence was preceded by a mean gap of $3250 \mathrm{msec}$. The MEG recording was performed in six blocks, each lasting $\sim 10 \mathrm{~min}$. The blocks were interleaved with $2-3 \mathrm{~min}$ breaks. During the recording the sentences were presented binaurally, and subjects were instructed to concentrate on the meaning of the sentences.

$M E G$ recording and data analysis. The recordings were conducted in a magnetically shielded room using the Neuromag Vectorview whole head system (Neuromag Ltd., Helsinki, Finland). The device contains 102 triple sensor elements composed of two orthogonal planar gradiometers and one magnetometer. The measured data were stored for off-line analysis. Signals were bandpass filtered to $0.03-100 \mathrm{~Hz}$ and sampled at $0.3 \mathrm{kHz}$. Separately for each type of sentence-ending word the signals were averaged from $200 \mathrm{msec}$ before to $1000 \mathrm{msec}$ after the presentation of the word. We also averaged signals time locked to the presentation of all the first words of the sentences. Both horizontal and vertical eye movements were recorded (bandpass $0.03-100 \mathrm{~Hz}$ ), and epochs contaminated by eye or lid movements were rejected. The mean number of artifact-free responses accepted for the averages was 84-87 for the four types of sentence-ending words and 319 for the first words of the sentences across all four conditions.

We analyzed the data in two ways. The areal mean signals (Hari et al., 1997) were calculated to get a rather crude but quick impression of the major features of the data over the whole head. The signals of each planar gradiometer were first squared, and then the signals of each sensor pair were summed together. Then, the square root of the signal was calculated. The channels were then grouped into 10 sections. Within each of the 10 sections the mean signals across all sensor pairs were averaged together for each individual. Group averages were calculated for the nonreading-impaired subjects and for the dyslexic individuals. A difference between waveforms was considered to be statistically significant at the $0.05,0.01$, and 0.001 probability levels when it exceeded 1.96, 2.58, and 3.29 times, respectively, the mean strength of the activation during the prestimulus period (from $-100 \mathrm{msec}$ to stimulus onset).

Equivalent current dipole (ECD) analysis (Hämäläinen et al., 1993) was used to reduce the neuromagnetic signals detected by the planar gradiometers into time behavior of distinct cortical areas. An ECD represents the orientation, strength, and center of the underlying electric current. Dipoles were localized individually for each subject using a 
a)

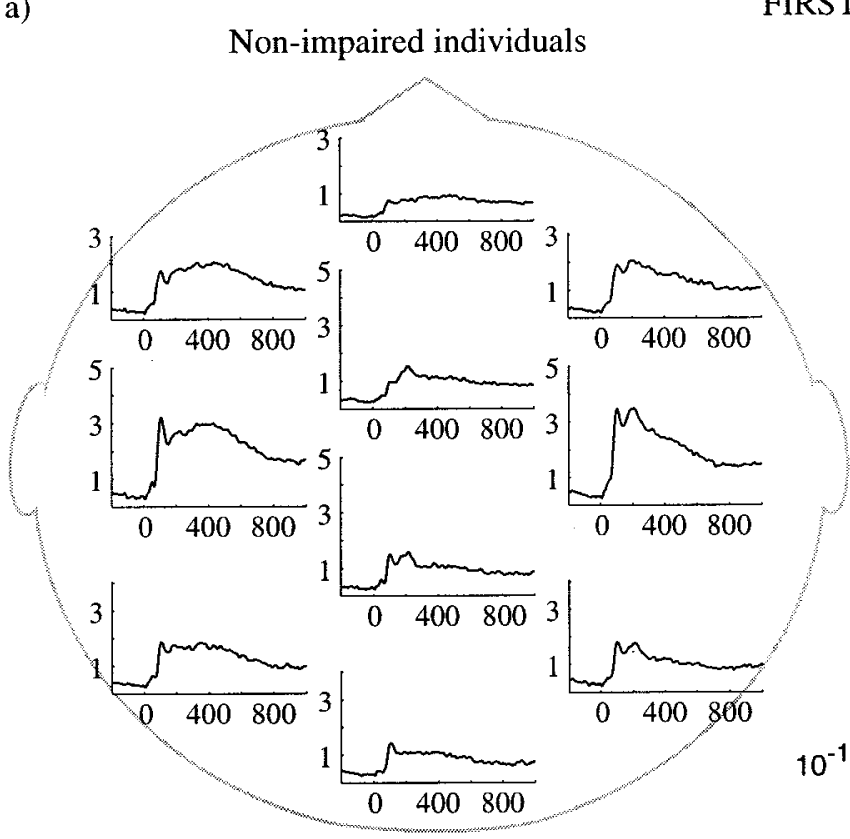

FIRST WORDS

\section{Dyslexic individuals}

b)
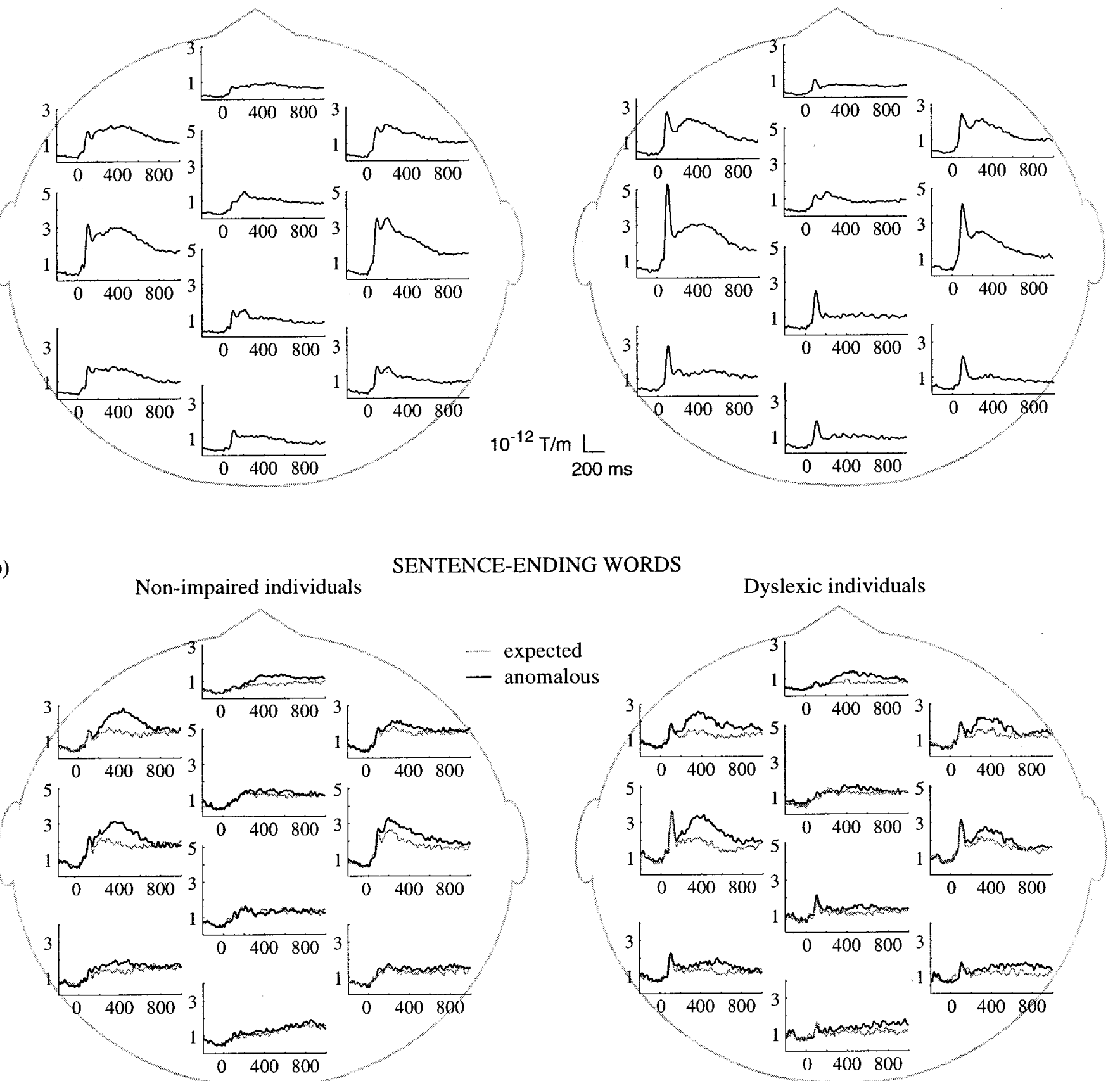

Figure 1. The areal mean signals. The signals for 10 channel sections area shown in control subjects (left) and in dyslexic subjects (right) both for the first words $(a)$ and for the expected and anomalous last words of the sentences $(b)$. Expected sentence-ending words are indicated with a gray line and the anomalous words with a black line.

subset of channels that ideally covered the distinct magnetic field patterns. After the dipoles had been localized they were included into a multidipole model and, keeping their orientation fixed, their amplitudes were allowed to be adjusted to achieve maximum explanation of the measured whole head dataset. The results gathered using dipole modeling were analyzed statistically using ANOVA models including both between- and within-subjects variables.

The location of sources was defined in head coordinates that were set by the nasion and two reference points anterior to the ear canals: $x$-axis was directed from the left (negative) to the right (positive) preauricular point, $y$-axis toward the nasion, and $z$-axis toward the vertex. At the beginning of the recording, the locations of four head position indicator coils were determined with respect to the sensors. The locations of these coils with respect to anatomical landmarks (nasion and ear canals) were measured with a three-dimensional digitizer. Because none of the subjects had magnetic resonance images available, the locations of the ECDs were presented on an average brain (see Appendix for further details on visualization).

\section{RESULTS}

\section{Areal mean signals}

Figure 1 illustrates the areal mean signals calculated for 10 channel sections in control and dyslexic subjects for the first words 
of the sentences (Fig. 1a) and for the expected and anomalous sentence-ending words (Fig. $1 b$ ). Both the very first words and the final words of the sentences elicited prominent activation over the left and right temporal channels. A similar signal could be seen over the anterior temporal-inferior frontal channel sections as well. The similarity of the signals on temporal and anterior temporal-inferior frontal channels suggests that the signal detected with these two channel sections is likely to have the same origin, possibly in the middle temporal region. Over other channel sections the activation was more modest and variable.

The activation in the temporal channel sections had two prominent peaks. The first peak was detected $\sim 100 \mathrm{msec}$ bilaterally in the temporal channels. The $\mathrm{N} 100 \mathrm{~m}$ responses to expected and anomalous sentence-ending words were equally strong. However, because the first words of the sentences were preceded by a longer silence, the $\mathrm{N} 100 \mathrm{~m}$ responses were stronger to the first than to the final words of the sentences $(p<0.05$ in control and $p<0.01$ in dyslexic subjects in the left hemisphere channels). In dyslexic individuals the left hemisphere $\mathrm{N} 100 \mathrm{~m}$ response was stronger than in nonreading-impaired individuals $(p<0.001$ for the first words of the sentences and $p<0.075$ for the sentence-ending words).

After the $\mathrm{N} 100 \mathrm{~m}$ response, the first words of the sentences and the anomalous sentence-ending words evoked prominent activation peaking $\sim 400 \mathrm{msec}$, whereas the activation evoked by the expected endings was weaker. This N400m response was statistically significantly stronger to anomalous than to expected sentence-ending words in the left temporal channels in both subject groups $(p<0.05)$. In the nonreading-impaired individuals the semantically sensitive activation in the left temporal channels peaked at $360 \mathrm{msec}$ and in the dyslexic individuals at 420 msec after word onset for the anomalous sentence-ending words. The possible differences in the timing of the $\mathrm{N} 400 \mathrm{~m}$ response between the subject groups was quantified by reducing the signals detected by the MEG sensors into time behavior of distinct cortical areas.

\section{Localization of neural populations underlying the $\mathrm{N} 100 \mathrm{~m}$ and $\mathrm{N} 400 \mathrm{~m}$ responses}

The location of the neural population generating the $\mathrm{N} 100 \mathrm{~m}$ response was determined at the peak of the response elicited by the first words of the sentences. The orientation of the current flow at the peak of the activation was perpendicular to the Sylvian fissure, toward the base of the brain. In all but one subject the magnetic field pattern was easily visible at the peak of the response and not obscured by simultaneous activation in nearby areas. In the one subject with a more complex right-hemisphere field pattern the interfering activation was removed using signalspace projection (Uusitalo and Ilmoniemi, 1997).

For the sustained activation peaking at $\sim 400 \mathrm{msec}$, the orientation of the current flow was also downward perpendicular to the Sylvian fissure. The location of the neural population generating this $\mathrm{N} 400 \mathrm{~m}$ response was computed at a time point when the field pattern was most clearly visible either in the data evoked by the first words or, in a few subjects, in the data gathered during the presentation of the anomalous sentence-ending words. The sustained downward oriented current flow was missing or the field pattern was too obscure to allow reliable source localization in the left hemisphere in one subject and in the right hemisphere in three subjects. In addition, in one subject neither the left nor the right-hemisphere response could be localized. In the remaining 14 subjects with bilateral localizable N400m and N100m re- sponses the mean distance between these two sources was $4.0 \mathrm{~mm}$ in the lateral-medial direction, $3.5 \mathrm{~mm}$ in the anterior-posterior direction, and $5.5 \mathrm{~mm}$ in the inferior-superior direction. The distances were, however, in opposite directions in the two hemispheres (lateral-medial and anterior-posterior directions) or very subtle (superior-inferior direction), and thus the difference between the $\mathrm{N} 100 \mathrm{~m}$ and $\mathrm{N} 400 \mathrm{~m}$ source coordinates did not reach statistical significance in a 2 (response type) $\times 3$ (coordinate) $\times$ 2 (hemisphere) $\times 2$ (subject group) ANOVA $\left(F_{(1,12)}=4.1 ; p<\right.$ $0.07)$. No statistically significant differences were detected between the two subject groups in the $\mathrm{N} 100 \mathrm{~m}$ or $\mathrm{N} 400 \mathrm{~m}$ source locations.

A statistically significant difference was detected in the $\mathrm{N} 100 \mathrm{~m}$ and N400m source orientations $\left(F_{(1,12)}=8.6 ; p<0.01\right)$; the $\mathrm{N} 100 \mathrm{~m}$ sources formed on average a $70^{\circ}$ angle with respect to the horizontal $y$-axis, whereas for the $\mathrm{N} 400 \mathrm{~m}$ sources the angle was $82^{\circ}$. Thus, based on source locations and orientations, the $\mathrm{N} 100 \mathrm{~m}$ and $\mathrm{N} 400 \mathrm{~m}$ responses seem to be generated by nonidentical but spatially adjacent neural populations.

\section{The strength and time behavior of semantic activation in the left hemisphere}

Because of the close proximity of the N100m and N400m sources, we included only the $\mathrm{N} 400 \mathrm{~m}$ sources in a multidipole model to account for the temporal activation over the entire analysis interval. In those two subjects in whom reliable source localization could not be achieved between 200 and $600 \mathrm{msec}$ in the left hemisphere, the $\mathrm{N} 100 \mathrm{~m}$ source was used, instead. In the right hemisphere the N100m source was used for four subjects. Sources generated in other cortical areas were included provided that they did not interfere with the detection of the time behavior of the $\mathrm{N} 400 \mathrm{~m}$ sources. In the left hemisphere these additional sources were generated either in anterior perisylvian areas, peaking $\sim 200$ $\mathrm{msec}$ (the P200m response was found in 6 of the 18 subjects) or in posterior perisylvian areas with a variable peak latency (in seven subjects). In the right hemisphere $\mathrm{P} 200 \mathrm{~m}$ activation was detected in nine subjects and posterior perisylvian activation in four subjects. The functional role of the $\mathrm{P} 200 \mathrm{~m}$ response is elusive, but it seems to be elicited especially reliably by noise bursts (Hari et al., 1987).

In the left hemisphere, anomalous sentence-ending words evoked statistically significant activation, i.e., around the peak the response strength exceeded 1.96 times the SD in the prestimulus period, for at least $100 \mathrm{msec}$ between 200 and $600 \mathrm{msec}$ in 18 subjects. In these 18 subjects the response for the anomalous sentence-ending words was during the same time period statistically significantly stronger than for the expected endings at least for $50 \mathrm{msec}$, i.e., the difference exceeded 1.96 times the SD in the prestimulus period. Figure $2 a$ depicts the spatial distribution of the $\mathrm{N} 400 \mathrm{~m}$ responses in those eight nonreading-impaired (left) and nine dyslexic subjects (right) that had both semantically sensitive and localizable activation in the left hemisphere between 200 and $600 \mathrm{msec}$. The individual sources are shown in reference to the center of activation of the $\mathrm{N} 100 \mathrm{~m}$ response (for additional information on source visualization, see Appendix).

The mean time behavior of activation in the left temporal region to the first words of the sentences and to the anomalous and expected sentence-ending words across those 8 control and 10 dyslexic subjects with semantically sensitive activation is shown in Figure 2, $b$ and $c$. The N100m response did not differ between the four types of sentence-ending words. However, after the $N 100 \mathrm{~m}$ response, $\sim 170 \mathrm{msec}$ after word onset in control subjects, the 
a)

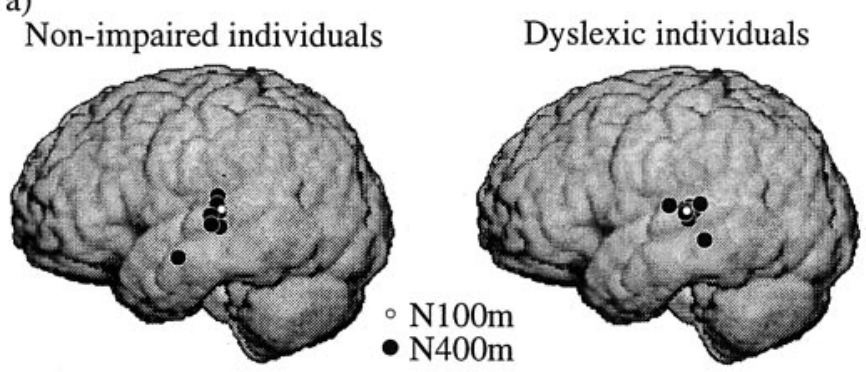

b)
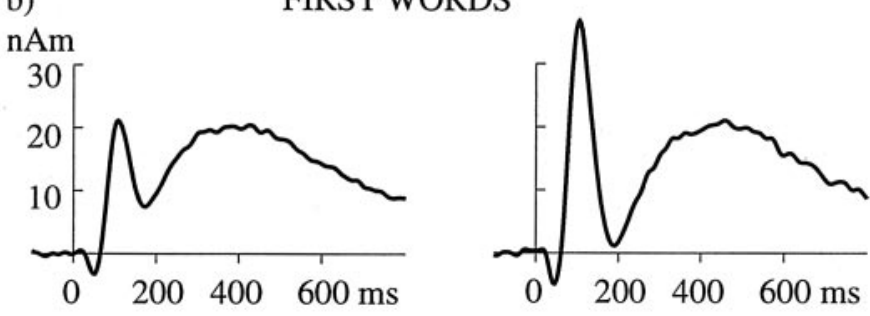

c)

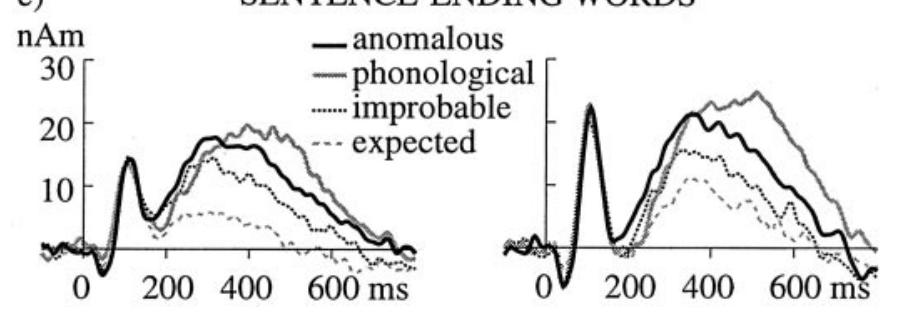

Figure 2. The N400m response locations and mean time behavior in the left hemisphere. $a$, The semantically sensitive and localizable $\mathrm{N} 400 \mathrm{~m}$ responses (black spheres) in eight nonreading-impaired (left) and nine dyslexic subjects (right) in the left hemisphere. The N100m response is shown as a white sphere. The mean time behavior of activation in the left temporal region for the first words $(b)$ and for the four types of sentenceending words $(c)$ across eight control and 10 dyslexic subjects with semantically sensitive activation.

anomalous sentence-ending words started to differ from the activation evoked by the expected endings. In each individual subject we measured the peak strength of the N400m source between 200 and $600 \mathrm{msec}$ to each sentence type. In a 4 (sentence type) $\times 2$ (subject group) mixed ANOVA, a significant main effect of sentence type was detected $\left(F_{(3,48)}=36.4 ; p<0.0001\right)$. The anomalous sentence-ending words elicited a statistically significantly stronger $\mathrm{N} 400 \mathrm{~m}$ response than the improbable sentence-ending words $\left(F_{(1,16)}=12.0 ; p<0.003\right)$ and the improbable evoked stronger activation than the expected endings $\left(F_{(1,16)}=28.6 ; p<\right.$ $0.0001)$. Thus, the $\mathrm{N} 400 \mathrm{~m}$ response strength was modulated by the semantic appropriateness of the sentence-ending word to preceding sentence context. For the phonological sentenceending words the activation was even stronger than for the anomalous endings $\left(F_{(1,16)}=7.6 ; p<0.01\right)$.

The timing of the broad $\mathrm{N} 400 \mathrm{~m}$ response was characterized by measuring the onset, the point in time when the activation had reached $50 \%$ of the maximum and the peak latency of the $\mathrm{N} 400 \mathrm{~m}$ response for the three types of unexpected sentence-ending words. A 3 (sentence type) $\times 3$ (time point) $\times 2$ (subject group) mixed ANOVA revealed a significant main effect of sentence type $\left(F_{(2,32)}=42.0 ; p<0.0001\right)$. The timing of the semantic activation did not differ between the anomalous and improbable endings, but for the phonological endings the semantic activation was delayed as compared with anomalous endings $\left(F_{(1,16)}=34.3 ; p \leq\right.$ $0.0001)$. The difference in peak latency for the anomalous and phonological sentence-ending words was on average $95 \mathrm{msec}$.

\section{The strength and latency of the N100m and N400m responses in dyslexic and nonreading-impaired individuals in the left hemisphere}

The waveforms depicting the mean time behavior of the left temporal activation in dyslexic and nonreading-impaired subjects are overlaid in Figure 3. The top row shows the responses to the first words of the sentences and the bottom row to the anomalous sentence-ending words. The mean strength and latency of the $\mathrm{N} 100 \mathrm{~m}$ and $\mathrm{N} 400 \mathrm{~m}$ responses are plotted on the right side of Figure 3. The peak strength and timing of the N100m response was measured from source waveforms that were generated by including only the $\mathrm{N} 100 \mathrm{~m}$ sources in the multidipole model.

A significant main effects of subject group were detected on the strength of the $\mathrm{N} 100 \mathrm{~m}$ response both to the first words $\left(F_{(1,17)}=\right.$ $11.0 ; p<0.004)$ and to the last words of the sentences $\left(F_{(1,17)}=\right.$ $5.8 ; p<0.03)$. The $\mathrm{N} 100 \mathrm{~m}$ responses were $\sim 40 \%$ stronger in dyslexic than nonreading-impaired individuals. The latency of the N100m response was identical in the two subject groups.

The N400m source strengths did not differ between the two subject groups. The main effect of subject group on the timing of the $\mathrm{N} 400 \mathrm{~m}$ response was significant both in the analysis of the responses to the first words of the sentences $\left(F_{(1,16)}=5.5 ; p<\right.$ $0.03)$ and to the unexpected sentence-ending words $\left(F_{(1,16)}=\right.$ 10.3; $p<0.005)$. In nonreading impaired subjects the $\mathrm{N} 400 \mathrm{~m}$ response evoked by the anomalous sentence-ending words started $\sim 170 \mathrm{msec}(\mathrm{SEM} \pm 15 \mathrm{msec})$ and peaked $\sim 325 \mathrm{msec}(\mathrm{SEM} \pm 20)$ after stimulus onset. In dyslexic subjects the response started at $205 \mathrm{msec}(\mathrm{SEM} \pm 10 \mathrm{msec})$ and peaked at $395 \mathrm{msec}(\mathrm{SEM} \pm 25$ $\mathrm{msec}$ ). On average the $\mathrm{N} 400 \mathrm{~m}$ response peaked $\sim 60 \mathrm{msec}$ later in the dyslexic subjects than in the nonreading-impaired individuals, when calculated across all unexpected sentence-ending words and the first words of the sentences.

\section{The strength and time behavior of semantic activation in the right hemisphere}

Anomalous sentence-ending words evoked statistically significant activation for at least $100 \mathrm{msec}$ between 200 and $600 \mathrm{msec}$ in the right hemisphere in 17 subjects. In 15 subjects (seven control and eight dyslexic subjects) during the same time period the response for the anomalous endings was statistically significantly stronger than for the expected endings. Figure 4 depicts the sources of the semantically sensitive N400m response in those seven nonreadingimpaired (left) and six dyslexic subjects (right) in whom N400m sources could be successfully localized (see Appendix for details of visualization). The mean time behavior of activation in the right temporal region to the first words of the sentences and to the anomalous and expected sentence-ending words across all 15 subjects with semantically sensitive activation is shown below.

The N400m peak amplitudes revealed significant difference between the four types of sentence-ending words in a 4 (sentence type) $\times 2$ (subject group) ANOVA $\left(F_{(3,39)}=24.5 ; p<0.0001\right)$. The anomalous sentence-ending words elicited a statistically significantly stronger $\mathrm{N} 400 \mathrm{~m}$ response than the improbable endings $\left(F_{(1,13)}=10.0 ; p<0.007\right)$, and the improbable endings evoked stronger activation than the expected endings $\left(F_{(1,13)}=24.6 ; p<\right.$ $0.0003)$. For the anomalous and phonological sentence-ending words the activation was equally strong. In a 3 (sentence type) $\times$ 3 (time point) $\times 2$ (subject group) mixed ANOVA, also the main 

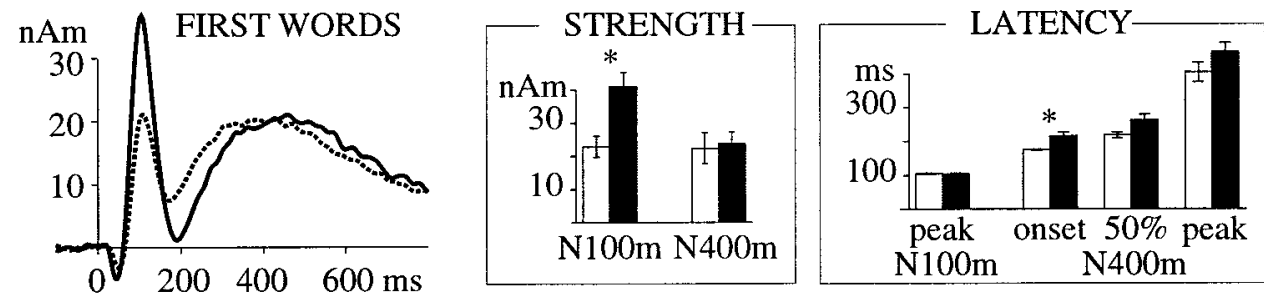

... non-impaired individuals 口

- dyslexic individuals
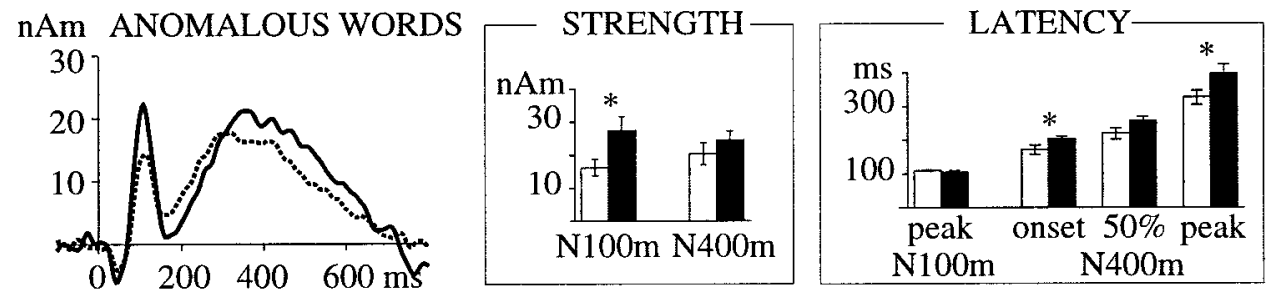

Figure 3. The strength and latency of $\mathrm{N} 100 \mathrm{~m}$ and $\mathrm{N} 400 \mathrm{~m}$ responses in the left hemisphere. The mean time behavior of the left temporal activation for the first words of the sentences (top row) and for the anomalous sentence-ending words (bottom row) in dyslexic (solid line) and nonreadingimpaired subjects (dotted line) is shown on the left. The mean $( \pm$ SEM $)$ strength and latency of the $\mathrm{N} 100 \mathrm{~m}$ and $\mathrm{N} 400 \mathrm{~m}$ responses are shown for control (white bars) and dyslexic subjects (black bars) on the right. Asterisks denote statistically significant differences between the subject groups at $p<0.05$. a)

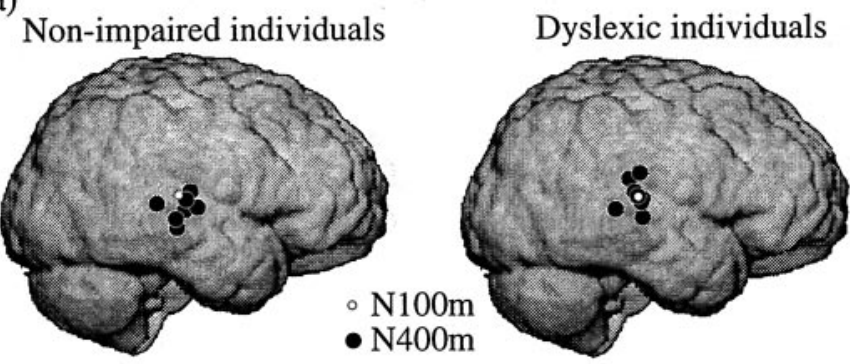

b)
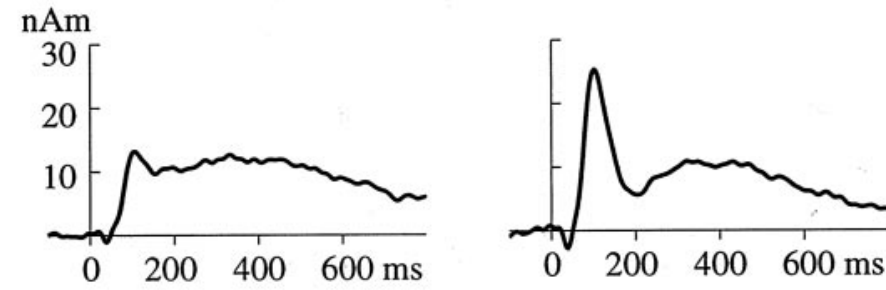

c)

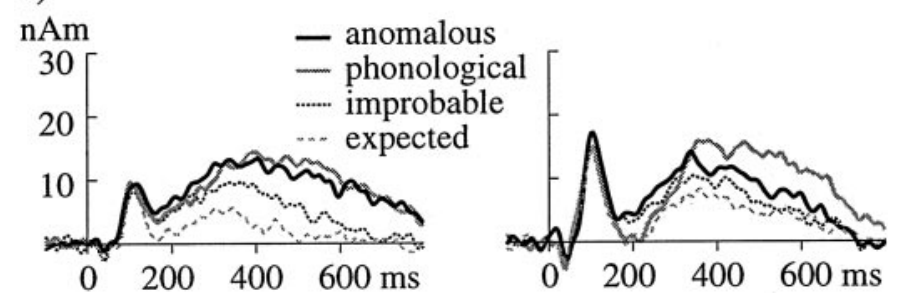

Figure 4. The N400m response locations and mean time behavior in the right hemisphere. $a$, The semantically sensitive and localizable $N 400 \mathrm{~m}$ responses (black spheres) in seven nonreading-impaired (left) and six dyslexic subjects (right) in the right hemisphere. The $\mathrm{N} 100 \mathrm{~m}$ response is shown as a white sphere. The mean time behavior of activation in the right temporal region to first words $(b)$ and to four types of sentence-ending words $(c)$ across seven control and eight dyslexic subjects with semantically sensitive activation.

effect of sentence type on latency reached statistical significance in the right hemisphere $\left(F_{(2,26)}=10.5 ; p<0.0005\right)$. The timing of the semantic activation was similar for the anomalous and improbable endings, but for the phonological endings the seman- tic activation was delayed in comparison with the anomalous endings $\left(F_{(1,13)}=10.5 ; p<0.006\right)$. The difference in peak latency for the anomalous and phonological sentence-ending words was on average $70 \mathrm{msec}$.

The effect of subject group on the N400m response strength or latency in the right hemisphere was nonsignificant for both the last words of the sentences and for the first words of the sentences.

\section{Comparisons of strength and timing of semantic activation in the left and right hemispheres}

In those 15 subjects with semantically sensitive activation in both the left and right hemispheres we compared the strength and time behavior of the activation. The timing of the $\mathrm{N} 400 \mathrm{~m}$ responses did not differ in the two hemispheres. However, for the N400m response strength a 2 (hemisphere) $\times 4$ (sentence type) $\times 2$ (subject group) mixed ANOVA revealed a significant main effect of hemisphere $\left(F_{(1,13)}=6.5 ; p<0.02\right)$. As indicated by the significant hemisphere by sentence type interaction $\left(F_{(3,39)}=5.7\right.$; $p<0.003)$, only the anomalous $\left(F_{(1,13)}=6.0 ; p<0.03\right)$, phonological $\left(F_{(1,13)}=8.5 ; p<0.01\right)$, and improbable sentence-ending words $\left(F_{(1,13)}=7.9 ; p<0.01\right)$ evoked a stronger $\mathrm{N} 400 \mathrm{~m}$ response in the left than in the right hemisphere, whereas the expected words evoked equally strong activation in the two hemispheres.

\section{DISCUSSION}

Naturally spoken words evoked two temporally and functionally distinct response patterns in the superior temporal lobe in nonreading-impaired and dyslexic adults. The activation peaking $\sim 100 \mathrm{msec}$, the $\mathrm{N} 100 \mathrm{~m}$ response, was found to reflect presemantic processing, and the activation $\sim 400 \mathrm{msec}$, the $\mathrm{N} 400 \mathrm{~m}$ response, semantic processing. Both of these processing stages differed between dyslexic and nonreading-impaired adults.

Activation peaking at $\sim 400 \mathrm{msec}$ in the superior temporal cortex, in close proximity of the supratemporal plane, was modulated by the semantic appropriateness of the sentence-ending words. The activation was stronger to semantically inappropriate sentence-ending words than to semantically appropriate, but unexpected, endings and weakest to semantically appropriate, expected endings. This semantic activation was clearly bilateral, although more robust and slightly more reliably detected in each individual in the left than right hemisphere. The $\mathrm{N} 400 \mathrm{~m}$ response was also evoked by the very first words of the sentences. Thus, as 
previous ERP studies of reading have indicated, the $\mathrm{N} 400 \mathrm{~m}$ response is elicited by most words within a sentence (Kutas et al., 1988), and the strength of the N400 response reflects the extent to which a word is semantically primed (Kutas and Hillyard, 1984).

Based on ERP data, it has been suggested that the N400 response evoked by spoken words is preceded and partly overlapped by an earlier negativity (or PMN) peaking between 200 and 300 msec (Connolly and Phillips, 1994; Hagoort and Brown, 2000; van den Brink et al., 2001) (but see also an opposing view by van Petten et al., 1999). The earlier negativity seems to be evoked by phonologically unprimed words and has been tentatively associated with a left anterior generator (Connolly et al., 2001). In the current MEG study we could not detect any separable component preceding the $\mathrm{N} 400 \mathrm{~m}$ response. Instead the $\mathrm{N} 400 \mathrm{~m}$ activation in the bilateral temporal lobes started $\sim 170$ msec covering the time periods of both the suggested early negativity and the N400. Naturally the results must be considered cautiously because the ERP and MEG responses are likely to have at least partly divergent generators. Particularly deep sources do not contribute to the measured magnetic field unlike to the electric potential. On the other hand, as the skull and the scalp distort the electric potential, the signals in each channel receive contribution from various cortical areas, whereas in the current MEG study, with the help of source modeling, the time behavior of left temporal lobe activation could be studied without interference from other cortical regions.

The onset of the N400m response occurred when only approximately one-third of the whole semantically anomalous word had been presented. For phonological sentence-ending words that shared their two or three first phonemes with the expected words, the N400m response was delayed by $\sim 100 \mathrm{msec}$. Taking into account the effect of coarticulation, $100 \mathrm{msec}$ is likely to be very close to the true point of uniqueness between the expected and phonological sentence-ending words. Thus, semantic processing seemed to be delayed only until emergence of the first evidence of acoustic-phonetic dissimilarity.

Psycholinguistic models differ in the ways they assume the speech signal is segmented to enable it to make contact with the distributed representations of word forms and meanings in the lexicon (Gaskell and Marslen-Wilson, 1997, 2001). Most current models assume that lexical access is based on phonemes (McClelland and Elman, 1986; Norris et al., 2000) or acoustic features (Marslen-Wilson and Warren, 1994) rather than on syllables (Segui et al., 1990). Our data, revealing only a $100 \mathrm{msec}$ delay in the phonological condition, agrees with phoneme or acoustic feature based access to the lexicon. This finding is also in line with the ERP study by Connolly and Phillips (1994) using similar stimuli in English. Based on behavioral data, the initial access to the lexicon is likely to take place $\sim 200 \mathrm{msec}$ after word onset (Marslen-Wilson and Tyler, 1980). This estimate corresponds nicely to the observed onset of the N400m response. From the very beginning of this activation, the responses evoked by expected and anomalous sentence-ending words started to diverge, indicating that semantic priming has an effect at the point lexical representations are accessed, but not at prelexical stages (e.g., during the $\mathrm{N} 100 \mathrm{~m}$ response).

The finding that lexicosemantic neural populations in the left superior temporal lobe are accessed almost online while phonetic information is being presented (Marslen-Wilson and Warren, 1994; Norris et al., 2000) has clear implications for imaging studies. In PET and fMRI studies, auditory semantic activation is often tapped by contrasting speech with reversed speech or pseudo-word listening (Howard et al., 1992; Price et al., 1996; Binder et al., 2000; Burton et al., 2001). Reversed speech is mostly incomprehensible but readily identified as speech because over $70 \%$ of the constituent letters can be correctly identified (Binder et al., 2000). As lexical access is based on subsyllabic speech units both pseudowords and reversed speech are likely to evoke lexicosemantic activation. Contrasting speech to reversed speech or pseudo-words could even cancel out most of the semantic activation elicited by any speech-like stimulus. However, when speech is contrasted to an acoustically complex nonlinguistic stimulus, lexicosemantic activation in addition to phonetic/phonological activation is likely to be revealed. Binder et al. (2000) recently compared the peak activation loci across four PET and fMRI studies (Démonet et al., 1992; Zatorre et al., 1992; Binder et al., 1997; Binder et al., 2000) where activation to different types of speech and nonlinguistic stimuli was contrasted. In these studies speech-specific activation was found in the areas of the superior temporal sulcus and superior temporal gyrus surrounding the auditory cortex. This is exactly the spatial distribution found in the current study. In addition, our study clearly reveals that the activation in the supratemporal plane, peaking $\sim 100 \mathrm{msec}$, is prelexical. Semantically sensitive neural populations are distributed in the surrounding superior temporal cortex, and the activation of these neurons peaks 300-400 msec after word onset. In the only fMRI study contrasting aurally presented semantically anomalous sentences to semantically appropriate sentences (Ni et al., 2000), activation was found in the left superior temporal cortex only slightly posterior to the center of activation found in the current study.

The semantic activation in the left hemisphere was delayed in the dyslexic individuals in the present study. This agrees with our previous findings in reading (Helenius et al., 1999a). Thus, it appears that dyslexic individuals have delayed access to semantic properties of the words also during the processing of natural spoken language. However, the qualitative aspects of spokenword segmentation appeared similar in the two subject groups (initial lexical access being based on acoustic-phonetic features). In addition to semantic delay, our earlier studies of reading in dyslexic individuals have indicated abnormal presemantic processing in the left inferior occipitotemporal cortex $\sim 150 \mathrm{msec}$ after word onset (Salmelin et al., 1996; Helenius et al., 1999b). Also in the current experiment, differences were detected in a time window preceding semantic activation, already in the $\mathrm{N} 100 \mathrm{~m}$ response.

Auditory input reaches the auditory cortex within $10-15 \mathrm{msec}$ after stimulus onset (Celesia, 1976; Liégeois-Chauvel et al., 1994), and thus the N100m response belongs in the category of long-latency auditory responses. The activation contributing to the $\mathrm{N} 100 \mathrm{~m}$ response is likely to originate predominantly in the planum temporale (Liégeois-Chauvel et al., 1994; Lütkenhöner and Steinstrater, 1998). Recent MEG studies have suggested that $\sim 150-200$ msec after stimulus onset the phonological categories have already been accessed (Phillips et al., 2000; Vihla et al., 2000). It is thus plausible that the neural populations underlying the N100m response could be involved in phonetic-phonological processing.

In dyslexic individuals the $\mathrm{N} 100 \mathrm{~m}$ response was abnormally large in the left hemisphere. One highly speculative interpretation of the aberrant auditory $\mathrm{N} 100 \mathrm{~m}$ response is that the neural populations in the posterior supratemporal plane have failed to specialize adequately for speech processing. Thus, speech sounds evoke activity in a large unspecialized neural population resulting 
in an atypically strong $\mathrm{N} 100 \mathrm{~m}$ response. If the abnormally strong $\mathrm{N} 100 \mathrm{~m}$ response in dyslexic individuals reflects their phonological difficulties, the N100m response should be normal for simple or complex nonspeech sounds. This is also what we recently found in the same subjects that participated in the present study (Helenius et al., 2002). However, many dyslexic individuals have difficulties in processing brief or rapidly successive nonspeech stimuli as well (Tallal, 1980; Hari and Kiesilä, 1996; Ahissar et al., 2000). Brief rapidly successive nonspeech stimuli have been reported to elicit abnormal auditory responses between 100 and $200 \mathrm{msec}$ in these individuals (Nagarajan et al., 1999). Thus, future studies are clearly needed to clarify the functional role and development of the $\mathrm{N} 100 \mathrm{~m}$ response and its relation to speech and nonspeech processing difficulties in dyslexia.

To summarize, auditory-phonological deficits associated with reading problems are manifested as differences in the cortical activation elicited by naturally spoken words. Although access to the meaning of words occurred in subsyllabic units in both nonreading-impaired and dyslexic individuals, semantic activation was delayed in dyslexia. This delay is likely to have resulted from difficulties in presemantic auditory processing, possibly reflected in the abnormal $\mathrm{N} 100 \mathrm{~m}$ response.

\section{Appendix}

According to a sizable literature on the location of the $\mathrm{N} 100 \mathrm{~m}$ response to simple tones, the center of activation lies just posterior to Heschl's gyrus in the planum temporale (Hari, 1990; Lütkenhöner and Steinstrater, 1998). Because individual MRIs were not available, sources of the N100m responses evoked by 1 $\mathrm{kHz} 50 \mathrm{msec}$ tones in a separate short recording session provided reference points in the left and right auditory cortex. The main experiment on speech processing lasted for $\sim 1 \mathrm{hr}$. Comparison of the location of the $\mathrm{N} 100 \mathrm{~m}$ response evoked by the first words across the entire measurement and only during the first third of the measurement showed that the subjects' heads had slipped downward in the helmet by $\sim 4 \mathrm{~mm}$ during the long session. After correction for this head movement, the mean location of the $\mathrm{N} 100 \mathrm{~m}$ response to the first words of the sentences in both hemispheres was within a few millimeters from the supratemporal auditory cortex, as indicated by comparison with the sources of the $\mathrm{N} 100 \mathrm{~m}$ response to $1 \mathrm{kHz}$ tones, and further supported by the average source locations projected on an average brain (created using elastic transformation, see Schormann et al., 1996). The $\mathrm{N} 400 \mathrm{~m}$ sources of each individual were projected onto the average brain with reference to the speech $\mathrm{N} 100 \mathrm{~m}$ response, the center of which was in each individual aligned to the supratemporal auditory cortex.

\section{REFERENCES}

Adlard A, Hazan V (1998) Speech perception in children with specific reading difficulties (dyslexia). Q J Exp Psychol A 51:153-177.

Ahissar M, Protopapas A, Reid M, Merzenich MM (2000) Auditory processing parallels reading abilities in adults. Proc Natl Acad Sci USA 97:6832-6837.

Binder JR, Frost JA, Hammeke TA, Cox RW, Rao SM, Prieto T (1997) Human brain language areas identified by functional magnetic resonance imaging. J Neurosci 17:353-362.

Binder JR, Frost JA, Hammeke TA, Bellgowan PSF, Springer JA, Kaufman JN, Possing ET (2000) Human temporal lobe activation by speech and nonspeech sounds. Cereb Cortex 10:512-528.

Bradley L, Bryant PE (1983) Categorizing sounds and learning to read: a causal connection. Nature 301:419-421.

Burton MW, Noll DC, Small SL (2001) The anatomy of auditory word processing: individual variability. Brain Lang 77:119-131.

Celesia GG (1976) Organization of auditory cortical areas in man. Brain 99:403-414.

Connolly JF, Phillips NA (1994) Event-related potential components reflect phonological and semantic processing of the terminal word of spoken sentence. J Cognit Neurosci 6:256-266.

Connolly JF, Phillips NA, Forbes KAK (1995) The effects of phonological and semantic features of sentence-ending words on visual eventrelated brain potentials. Electroencephalogr Clin Neurophysiol 94:276-287.

Connolly JF, Service E, D'Arcy RCN, Kujala A, Alho K (2001) Phonological aspects of word recognition as revealed by high-resolution spatio-temporal brain mapping. NeuroReport 12:237-243.

Démonet J-F, Chollet F, Ramsay S, Cardebat D, Nespoulous J-L, Wise R, Rascol A, Frackowiak R (1992) The anatomy of phonological and semantic processing in normal subjects. Brain 115:1753-1768.

Gaskell MG, Marslen-Wilson WD (1997) Integrating form and meaning: a distributed model of speech perception. Lang Cogn Processes 12:613-656.

Gaskell MG, Marslen-Wilson WD (2001) Lexical ambiguity resolution and spoken word recognition: bridging the gap. J Mem Lang 44:325-349.

Hagoort P, Brown CM (2000) ERP effects of listening to speech: semantic ERP effects. Neuropsychologia 38:1518-1530.

Hämäläinen M, Hari R, Ilmoniemi RJ, Knuutila J, Lounasmaa OV (1993) Magnetoencephalography theory, instrumentation, and applications to noninvasive studies of the working human brain. Rev Mod Phys 65:413-497.

Hari R (1990) The neuromagnetic method in the study of the human auditory cortex. In: Auditory evoked magnetic fields and potentials: advances in audiology (Grandori F, Hoke M, Romani G, eds), pp 222-282. Basel: Karger.

Hari R, Kiesilä P (1996) Deficit of temporal auditory processing in dyslexic adults. Neurosci Lett 205:138-140.

Hari R, Pellizzone M, Mäkelä JP, Hällström J, Leinonen L, Lounasmaa OV (1987) Neuromagnetic responses of the human auditory cortex to on- and offsets of noise bursts. Audiology 26:31-43.

Hari R, Portin K, Kettenmann B, Jousmäki V, Kobal G (1997) Righthemisphere preponderance of responses to painful $\mathrm{CO}_{2}$ stimulation of the human nasal mucosa. Pain 72:145-151.

Helenius P, Salmelin R, Service E, Connolly J (1998) Distinct time courses of word and context comprehension in the left temporal cortex. Brain 121:1133-1142.

Helenius P, Salmelin R, Service E, Connolly J (1999a) Semantic cortical activation in dyslexic readers. J Cogn Neurosci 11:535-550.

Helenius P, Tarkiainen A, Cornelissen P, Hansen PC, Salmelin R (1999b) Dissociation of normal feature analysis and deficient processing of letter-strings in dyslexic adults. Cereb Cortex 9:476-483.

Helenius P, Salmelin R, Richardson U, Leinonen S, Lyytinen H (2002) Abnormal auditory cortical activation in dyslexia $100 \mathrm{~ms}$ after speech onset. J Cognit Neurosci, in press.

Howard D, Patterson K, Wise R, Brown WD, Friston K, Weiller C, Frackowiak R (1992) The cortical localization of the lexicons: positron emission tomography evidence. Brain 115:1769-1782.

Kutas M, Federmeier K (2000) Electrophysiology reveals semantic memory use in language comprehension. Trends Cognit Sci 4:463-470.

Kutas M, Hillyard SA (1980) Reading senseless sentences: brain potentials reflect semantic incongruity. Science 207:203-205.

Kutas M, Hillyard SA (1984) Brain potentials during reading reflect word expectancy and semantic association. Nature 307:161-163.

Kutas M, Van Petten C, Besson M (1988) Event-related potential asymmetries during the reading of sentences. Electroencephalogr Clin Neurophysiol 69:218-233.

Leinonen S, Müller K, Leppänen PHT, Aro M, Ahonen T, Lyytinen H (2001) Heterogeneity in adult dyslexic readers: relating processing skills to the speed and accuracy of oral text reading. Read Writ 14:265-296.

Liégeois-Chauvel C, Musolino A, Badier JM, Marquis P, Chauvel P (1994) Evoked potentials recorded from the auditory cortex in man: evaluation and topography of the middle latency components. Electroencephalogr Clin Neurophysiol 92:204-214.

Lundberg I, Olofsson A, Wall S (1980) Reading and spelling skills in the first school years predicted from phonemic awareness skills in kindergarten. Scan J Psychol 21:159-173.

Lütkenhöner B, Steinstrater O (1998) High-precision neuromagnetic study of the functional organization of the human auditory cortex. Audiol Neurootol 3:191-213.

Lyytinen H (1997) In search of precursors of dyslexia. In: Dyslexia: biology, cognition and intervention (Snowling M, Hulme C, eds), pp. 97-107. London: Whurr.

Marslen-Wilson WD, Tyler LK (1980) The temporal structure of spoken language understanding. Cognition 8:1-71.

Marslen-Wilson WD, Warren P (1994) Levels of perceptual representation and process in lexical access: words, phonemes, and features. Psychol Rev 101:653-675.

McClelland JL, Elman JL (1986) The TRACE model of speech perception. Cogn Psychol 18:1-86.

Nagarajan S, Mahncke H, Salz T, Tallal P, Roberts T, Merzenich MM 
(1999) Cortical auditory signal processing in poor readers. Proc Natl Acad Sci USA 96:6483-6488.

Ni W, Constable RT, Mencl WE, Pugh KR, Fulbright RK, Shaywitz SE, Shaywitz BA, Gore JC, Shankweiler D (2000) An event-related neuroimaging study distinguishing form and content in sentence processing. J Cognit Neurosci 12:120-133.

Norris D, McQueen JL, Cutler A (2000) Merging information in speech recognition: feedback is never necessary. Behav Brain Sci 23:299-325.

Osterhout L, Holcomb PJ (1995) Event-related potentials and language comprehension. In: Electrophysiology of mind (Rugg MD, Coles MGH, eds), pp 171-215. Oxford: Oxford UP.

Phillips C, Pellathy T, Marantz A, Yellin E, Wexler K, Poeppel D, McGinnis M, Roberts T (2000) Auditory cortex accesses phonological categories: an MEG mismatch study. J Cognit Neurosci 12:1038-1055.

Price CJ, Wise RJ, Warburton EA, Moore CJ, Howard D, Patterson K, Frackowiak RS, Friston KJ (1996) Hearing and saying. The functional neuro-anatomy of auditory word processing. Brain 119:919-931.

Raven JC, Court JH, Raven J (1992) Standard progressive matrices. Oxford: Oxford Psychologists.

Reed MA (1989) Speech perception and the discrimination of brief auditory cues in reading disabled children. J Exp Child Psychol 48:270-292.

Salmelin R, Service E, Kiesilä P, Uutela K, Salonen O (1996) Impaired visual word processing in dyslexia revealed with magnetoencephalography. Ann Neurol 40:157-162.

Scarborough HS (1990) Very early language deficits in dyslexic children. Child Dev 61:1728-1743.
Schormann T, Henn S, Zilles K (1996) A new approach to fast elastic alignment with application to human brains. Lect Notes Comp Sci 1131:337-342.

Schülte-Körne G, Deimel W, Bartling J, Remschmidt H (1998) Auditory processing and dyslexia: evidence for a specific speech processing deficit. NeuroReport 9:337-340.

Segui J, Dupoux E, Mehler J (1990) The role of the syllable in speech segmentation, phoneme identification, and lexical access. In: Cognitive models of speech processing (Altmann GTM, ed), pp 263-280. London: MIT.

Tallal P (1980) Auditory temporal perception, phonics, and reading disabilities in children. Brain Lang 9:182-198.

Uusitalo MA, Ilmoniemi RJ (1997) Signal-space projection method for separating $\mathrm{MEG}$ or EEG into components. Med Biol Eng Comp 35:135-140.

van den Brink D, Brown CM, Hagoort P (2001) Electrophysiological evidence for early contextual influence during spoken-word recognition. J Cognit Neurosci 13:967-985.

van Petten C, Coulson S, Rubin S, Plante E, Parks M (1999) Time course of word identification and semantic integration in spoken language. J Exp Psychol Learn Mem Cogn 18:380-393.

Vihla M, Lounasmaa OV, Salmelin R (2000) Cortical processing of change detection: dissociation between natural vowels and twofrequency complex tones. Proc Natl Acad Sci USA 97:10590-10594.

Zatorre RJ, Evans AC, Meyer E, Gjedde A (1992) Lateralization of phonetic and pitch discrimination in speech processing. Science 256: $846-849$ 